\title{
LOS ANTROPÓNIMOS: NOCIONES TEÓRICAS Y MODALIDADES DE TRANSFERENCIA (Francés-español)
}

M.' Rosario Ozaeta Gálvez

UNED. Madrid

\section{RESUMEN}

La transferencia de los antropónimos es un tema de indudable atractivo para cualquier estudioso de la traducción, y supone un reto para los traductores. ¿Los nombres de persona se transfieren? es el punto de partida del presente artículo, y la respuesta, aunque afirmativa, se matiza en función de la diversidad y la peculiaridad de aquéllos. Partiendo de unas imprescindibles nociones teóricas, mediante las que tratamos de describir - muy sucintamente- la naturaleza, funciones y particularidades de los antropónimos, nos situamos en condiciones de abordar las modalidades de su transferencia. Dichas modalidades, que han sido deducidas a partir del estudio de textos auténticos de determinados autores, seleccionados en función de su idoneidad en este campo, son ilustradas, a su vez, en un segundo momento, en un apartado de aplicaciones, que conduce a unas conclusiones plurales que confluyen en la afirmación de la capacidad de los nombres de persona como indudables transmisores de connotaciones y portadores de valores múltiples. 


\section{INTRODUCCIÓN}

En el estudio de la transferencia de los antropónimos es indispensable la inclusión de algunos aspectos teóricos, que revelan una gran diversidad de enfoques y ofrecen un buen número de claves.

El nombre propio ha sido considerado bajo distintas ópticas y ha sido objeto de numerosas clasificaciones, que comprenden categorías tan dispares como los nombres de persona -que, a su vez, se aplican a nombres, apellidos, hipocorísticos, apodos, seudónimos, epónimos...-, de animales y de lugares; de títulos, instituciones, marcas, e incluso de festividades, como Pascua, Todos los Santos, o Pentecostés. En todas las categorías mencionadas se hace evidente el carácter deíctico que entraña el nombre propio.

De entre ellas, hemos seleccionado en principio la clasificación entre nombres de personas y lugares, por juzgarla más apta para este estudio, que se orienta a las modalidades de transferencia. La onomástica, disciplina que se ocupa del estudio de antropónimos y topónimos, se ha visto marginada frente a otras ciencias limítrofes como la geografía, la historia, la genealogía, la lexicología y la sociología - que, por otra parte, le han servido de apoyo-, aunque trata de reivindicar día a día su estatuto y su peso específico. A su vez, el estudio de los antropónimos ha sido relegado frente al de los nombres de lugares, que ha sido objeto de numerosos trabajos, pero actualmente, aquél viene suscitando un creciente interés, y se les dedica una progresiva atención a sus distintos aspectos. La diversidad, riqueza y complejidad de los antropónimos han sido factores determinantes en su elección como objeto del presente artículo.

El estudio de los nombres de persona ha discurrido principalmente por dos vías; la primera de ellas, de carácter filológico, considera su origen, formación, clasificación, propagación y distribución, y la segunda, de naturaleza filosófica, se ocupa de la espinosa cuestión de su capacidad referencial, que plantea si los nombres son o no portadores de sentido. Pero el campo de la antroponimia es, como se ha señalado, mucho más extenso. ${ }^{1}$

Así pues, no es posible abordar el estudio de los antropónimos desde una perspectiva única, por lo que, por una parte, se van a esbozar algunas nociones

1 Numerosos autores manifiestan la amplitud de dicho campo directa o indirectamente. Eugène Vroonen, en su estudio Les noms de personnes dans le monde (1967), ya señalaba la presencia de un interés común en colectivos tan dispares como los etnógrafos, sociólogos, genealogistas, críticos, cronistas, novelistas, etimólogos, oradores, historiadores y lingüistas. Cabe citar, además, entre otros, a Pierre Swiggers (1989), que se ocupa de los nombres como objetos sociolingüísticos y socioculturales, y a Mari-Noelle Gary-Prieur (1991a), que, partiendo de la lingüística, se centra en la interpretación de los nombres propios por los locutores. 
teóricas en torno a su carácter y funcionalidad y, por otra, van a ser considerados diversos criterios, que varían según las perspectivas adoptadas.

\section{ASPECTOS TEÓRICOS}

\subsection{Naturaleza y funciones}

En la descripción de los antropónimos merecen ser destacados dos rasgos en particular: su carácter clasificador y su potencial simbólico, que les confieren la capacidad de transmitir determinados valores poéticos, culturales y étnicos. En su calidad de clasificadores, los nombres indican la pertenencia de un individuo a un grupo social y, a veces, profesional, el origen geográfico, el rango o estatuto de nacimiento, y aportan una información de identidad sexual y hasta generacional, referida a las franjas de edad. Como símbolos, representan un sistema de valores y creencias (nombres teóforos, míticos...), participando de una determinada visión del mundo.

Los nombres desempeñan, pues, de acuerdo con los referidos caracteres, funciones clasificadoras y simbólicas, a las que hay que sumar otros empleos prototípicos, como son los de identificación y nominación. La identificación es la función primaria por excelencia, en virtud de la cual, según determinados criterios de clasificación, se establece un vínculo singular entre una entidad y un nombre, lo que remite a la función referencial y al carácter deíctico de éste.

Los nombres poseen, además, la capacidad de atraer la atención de los demás, de interpelar, desempeñando una función vocativa. Pueden, asimismo, actuar como atributos y como epítetos según los contextos sintácticos en los que se hallan ubicados; el nombre que se encuentra en posición de atributo expresa habitualmente la identidad (Le directeur de cette entreprise est Julien : «El director de esta empresa es Julián»), pero también pueden desempeñar una función predicativa cuando su contenido es descriptivo (Si cet enfant continue à étudier, il va devenir Newton: «Si este niño sigue estudiando va a convertirse en un Newton»). Los nombres propios que forman parte de construcciones «metafóricas» (según la terminología de K. Jonasson, 1991, 1994), entrañan un contenido connotativo -como se puede apreciar en numerosos ejemplos (Claude est le Don Juan du village : «Claudio es el Don Juan del pueblo" es uno de ellos)-, constituyendo un caso especial desde la óptica de su transferencia, que se rige por coordenadas culturales.

Los antropónimos en función de epíteto se emplean, en cambio, como «nombres puros» o «no modificados». K. Jonasson (1994) establece una distinción entre nombres epítetos de identificación ( $L a$ mère $U b u, M o n$ mari 
Jean: «La madre Ubu», «Mi marido Juan»), de determinación (La rue Molière : «La calle Molière») y de calificación ( $\mathrm{J}$ 'aurais aimé voir apparaittre $\mathrm{Ha}$ rrison-Indiana : «Me hubiera gustado ver aparecer a Harrison-Indiana»).

Antes de abordar las particularidades de los antropónimos bajo distintas perspectivas, vamos a desarrollar algunos de los conceptos mencionados, por la importancia que revisten desde la óptica de la transferencia.

\subsection{La distinción: nombres propios modificados/no modificados}

Los nombres propios no modificados designan a un individuo específico. En este empleo prototípico, han sido denominados noms propres incarnés (Gardiner, 1954), désignateurs rigides (Kripke, 1972), noms singuliers (Buyssens, 1973), noms purs (Jonasson, 1994). Por el contrario, los nombres propios modificados pierden su carácter único en determinados contextos sintácticos que incluyen artículos determinados o indeterminados, adjetivos indefinidos o demostrativos u otras expansiones a la derecha y a la izquierda del nombre propio, que puede llegar a adoptar la forma de plural. La función de los nombres propios modificados deja de ser la de identificar, para ser descriptiva o caracterizadora.

Según una clasificación que engloba criterios de distintos autores, entre los que destacamos el de K. Jonasson, existen varios tipos de nombres propios modificados. El primero de ellos, dénominatif, "denominativo», se define por la construcción: «être appelé, s'appeler $N p »^{2}$ («ser llamado, llamarse Np»), que puede ser introducida mediante varios determinantes, incluido el demostrativo ce, «este», y mediante las expansiones « un certain", " un soi-disant $» . . .($ «un tal», «un supuesto»...):

Il y avait sept Paul sur ma liste : "Había siete Pablos en mi lista» Il n'y a pas d'Eric dans ce hureau : "No hay ningún Eric en este despacho»

El segundo tipo, que se aplica al caso en que un particular asume diversas manifestaciones, ha sido denominado de fractionnement, "de fraccionamiento», por K. Jonasson (1994) y G. Kleiber (1991); de multiplication y de modalisation, «de multiplicación» y «de modalización» por M.-N. Gary Prieur $(1989,1991 b)$. Según esta autora, el individuo no se fracciona, sino que está

\footnotetext{
2 Np: Nom propre («Nombre propio»).
} 
representado en un determinado universo: « On peut rattacher la présence du déterminant dans tous les cas à une multiplication du référent, que cette multiplication soit posée ou présuposée » (1989: 129). La construcción «leNpExp ${ }^{3}$ («elNpExp») es la más frecuente, y la expansión es obligatoria a la derecha del nombre propio:

Il est devenu en 1968 le Michel anarchiste que vous admirez : «En 1968 se convirtió en el Miguel anarquista al que admiráis»

Con respecto a la construcción « unNpExp» («unNpExp»), es situada por Gary Prieur en el universo del discurso. El siguiente ejemplo ilustra dicho empleo:

On sait tout ce que cette hypothèse d'un Mallarmé meurtrier du langage doit à Maurice Blanchot (Barthes, «L'écriture et le silence »: 179) : «Es bien sabido todo lo que le debe a Maurice Blanchot la hipótesis de un Mallarmé destructor del lenguaje»

El nombre propio métaphorique, «metafórico», es introducido generalmente por un determinante - aunque existen empleos en función apositivay suele acompañarse de diversos complementos, que pueden aparecer pospuestos. De gran productividad, es éste el empleo que más nos interesa desde el punto de vista de la traducción. Las posibilidades morfosintácticas son diversas, siendo poco utilizada la adjunción de $s$. Los ejemplos siguientes, procedentes de las Fábulas de La Fontaine, ilustran algunos de los empleos más frecuentes:

Le Phaéton d'une voiture à foin

Vit son char embourbé

(VI. 18, vv. 1-2)

... La voilà donc compagne

De certaines Philis qui gardent les dindons

(VII. 2, vv. 24-25)

Quatre Mathusalems bout à bout ne pourraient

Mettre à fin ce qu'un seul désire

(VIII. 25, vv. 47-48)

J'ai lu chez un conteur de Fables,

Qu'un second Rodilard, l'Alexandre des Chats

L'Attila, le fléau des Rats

(III. 18, vV. 1-3)

3 Exp: Expansion («Expansión»). 
C'étaient deux vrais Tartufs, deux archipatelins (IX. 14, v. 3)

Et, nouvel Empédocle aux flammes condamné,

(...) Il se lança dedans

(IX. 12, vv. 13, 15)

La función de estos nombres es descriptiva, y como pueden vehicular datos culturales consistentes en determinadas propiedades o en un papel social concreto, exigen a veces una adaptación a la cultura de llegada. Los nombres metafóricos sufren un diferente grado de lexicalización; conviene, por ello, prestar una especial atención a los eventuales problemas de opacidad o de incompatibilidad cultural en el caso de los nombres más lexicalizados.

Por último, citaremos las construcciones exemplaires, «ejemplares», próximas a las metafóricas, que incluyen un nombre de acusada notoriedad. Pueden desempeñar diversas funciones sintácticas, pero su estructura es muy simplificada, sin expansión: « unNp» («unNp»). En este caso, el artículo contribuye a subrayar la especificidad del nombre:

... la poésie moderne - celle d'un Hugo, d'un Rimbaud ou d'un Char - est saturée de style... (Barthes, «Qu'est-ce que l'écriture ? »: 146) : «... la poesía moderna - la de un Hugo, un Rimbaud o un Char- está saturada de estilo...»

\subsection{Perspectivas de estudio}

El estudio de los antropónimos ha sido abordado bajo diversas ópticas, que pueden revestir un carácter linguístico, pragmático, cognitivo y antropológico. Dichos aspectos van a ser descritos brevemente.

\subsubsection{Aspectos lingüísticos}

Desde un punto de vista lingüístico, es posible estudiar los nombres de persona a través de diversos niveles, de naturaleza fonético-fonológica, gráfica, morfosintáctica y semántica.

La carencia de un sistema fijo fonético-fonológico en los nombres plantea problemas en el momento de su incorporación a otro sistema lingüístico; en tal caso, la tendencia que ha prevalecido habitualmente ha sido la de su naturalización, consistente en adaptar dichos nombres al sistema fonológico y gráfico de llegada tras una época transitoria de coexistencia parcial entre los dos sistemas. Sin embargo, actualmente se está imponiendo cada vez más la tendencia 
a mantener los rasgos de la lengua original, es decir, a respetar la integridad de su sistema.

Otra cuestión es la pérdida de la opacidad del nombre, y la capacidad de éste para transmitir determinados valores fónicos ${ }^{4}$. A propósito del simbolismo fónico, que ha sido un tema ampliamente debatido, tanto la imagen sonora como el código ortográfico pueden suscitar connotaciones, siendo innegable la capacidad sugestiva del nombre propio ${ }^{5}$. Así, los antropónimos pueden transmitir valores expresivos de sensualidad, comicidad, sonoridad o exotismo, que constituyen una limitación, pero también un reto para el traductor.

A un nivel gráfico, es importante mencionar la mayúscula, que, aunque ha sido considerada como uno de los rasgos definitorios del nombre propio, no lo es realmente más que en los nombres «puros» de personas, si se tienen en cuenta algunos casos de lexicalizaciones metonímicas - toponímicas, patronímicas...- ( Du bourgogne : «El borgoña»; Un mécène : «Un mecenas»...) u otros de nombres comunes con mayúscula (La Raison : «La Razón»; L'Amour : «El Amor»...). ${ }^{6}$

Desde un plano morfosintáctico, numerosos autores se han planteado el estatuto gramatical que correspondería a los nombres propios. La dificultad en la atribución de marcas morfológicas o sintácticas a los antropónimos obedece, en primer lugar, a su carencia de restricciones morfológicas, ya que la mayoría de las partes del discurso pueden constituir un nombre propio, como muestran los siguientes ejemplos:

Elle et Que-si-que-non, son frère,

Avecque Tien-et mien son père

(La Fontaine, VI. 20, pp. 6-7)

Le Médecin Tant-pis allait voir un malade

Que visitait aussi son confrère Tant-mieux (Id., V. 12, pp. 1-2)

${ }^{4}$ François Rigolot expone así su criterio respecto a la motivación de los nombres propios literarios: «... le nom propre, toponyme ou anthroponyme, peut se charger de signification au même titre que les autres mots du texte; le référent s'estompe alors pour privilégier le rapport du signifiant au signifié. Participant à la 'littéralité ' du texte, le nom propre semble être à la recherche d'une 'remotivation 'phonique qui n'a rien à voir avec son origine appellative » (1977: 12).

s Francisco Yndurain, en su artículo «Comparatismo y poligénesis» (1992), alude incluso a la posibilidad de que varios autores resientan los mismos efectos o asociaciones suscitadas por la mera audición de los nombres, debido a una «connotación poética».

' Según M.-N. Gary-Prieur: « La différence signalée par la majuscule tient bien sûr à la spécificité du nom propre, qui n'est associé, comme le nom commun, à un concept. Elle est aussi reliée à des différences de comportement dans les énoncés ". (1991a: 23). 
Por otra parte, no se puede afirmar la invariabilidad del nombre, que, de hecho, puede variar en género (Denis, Denise; Juan, Juana) y adoptar el plural en determinados casos (nombres de dinastías, apellidos...). El rasgo de ausencia de artículo tampoco resulta definitorio, ya que no es aplicable más que en el caso de los nombres «puros», mientras que en algunos empleos «modificados», como se ha señalado, los nombres pueden verse acompañados por determinantes y otras expansiones.

Los factores mencionados no hacen sino subrayar la especificidad de los nombres propios de persona. El criterio de $\mathrm{K}$. Jonasson resume así dicha problemática: «L'intéressant est que, dépourvu ou accompagné de l'article, le nom propre paraît difficile à intégrer dans le cadre syntaxique normal de la langue » (1994: 11).

Finalmente, es digna de mención la polémica en torno a la capacidad referencial del nombre, que obtiene distintas respuestas, desde la teoría del nombre vacío de sentido, defendida por numerosos autores (Mill, 1866; Molino, 1982; Récanati, 1983...), hasta la teoría que interpreta el sentido del nombre como una descripción de su referente (Frege, 1971; Searle, 1971), pasando por soluciones intermedias (Kleiber, 1981). Las teorías posteriores son menos categóricas, y algunos autores tratan de conciliar ambas posturas (López, 1985; Wilmet, 1991). Según M. T. Espinal (1992), la disparidad de análisis se debería a la existencia de nombres opacos y transparentes y en concreto, a la capacidad de estos últimos para contener material léxico descriptivo, aun manteniéndose arbitraria su asociación a los individuos de referencia. Estos criterios nos parecen más adecuados, ya que la aptitud para significar de los nombres propios resulta obvia si se considera su capacidad de transmitir indicaciones de sexo, origen geográfico, etc., así como su carácter evocador, que ya han sido mencionados. Como afirma C. Kerbrat: " Chaque nom draine avec lui l'ensemble de connaissances que les actants de l'énonciation possèdent sur le porteur du nom » (1977: 178).

\subsubsection{Aspectos pragmáticos, cognitivos y antropológicos}

Otros acercamientos revisten un carácter pragmático y cognitivo, y son defendidos por diversos autores. J. Molino (1982), que representa el primero de ellos, tiene en cuenta las condiciones de la enunciación y sostiene que el nombre no es una simple etiqueta, puesto que es susceptible de otros usos además del puramente referencial. K. Jonasson (1994), por su parte, rechazando la perspectiva referencial, adopta una óptica cognitiva, según la cual, los nombres propios tienen la función de nombrar, afirmar y mantener una individualidad, 
y proporcionan indicios de gran utilidad para organizar la realidad y el mundo percibidos.

Los estudios de carácter antropológico, recogidos en numerosas obras y diccionarios especializados, reúnen diversos aspectos —etimológicos, étnicos, sociológicos...- de carácter eminentemente cultural. Eugène Vroonen, en su obra Les noms de personnes dans le monde, clasifica los sistemas antroponímicos según su inspiración, religiosa o profana. Entre los nombres religiosos, incluye nombres de origen cristiano (personajes bíblicos, teóforos, de santos), de origen hebreo (la Virgen, los apóstoles), de origen helénico (ángeles, arcángeles), de origen romano (Paul), germánico (Charles)... Los nombres de inspiración profana revisten un carácter igualmente diverso, y pueden estar forjados a partir de fenómenos naturales (Neige) o constituir creaciones artificiales o arbitrarias, como los nombres atribuidos por los pueblos primitivos. Otros nombres son metafóricos, o alegóricos (Liberté, Prudence).

La elección de los nombres obedece a distintas razones, que van desde la originalidad, la evocación, la estética, el esnobismo o la moda, a factores étnicos o a motivos religiosos, que pueden responder a la tradición y a las normas sociales. Por ejemplo, los nombres germánicos guardan, en su origen, la expresión de un deseo para el futuro del recién nacido. Es más, los antropónimos han llegado a ser objeto de reglamentación en algunas etapas de la historia, como cuando, a raíz del Concilio de Trento (1563), era obligada la imposición de un nombre de santo en el bautismo. Los nombres se convierten, así, en elementos reveladores de las tendencias dominantes de una sociedad determinada en un momento dado. En la Biblia, el nombre propio reviste un carácter sagrado, lo que ha podido inspirar a algunos autores, que lo han relacionado con el temperamento de su portador, y que reflejan dicha concepción en sus obras, recogiendo los caracteres atribuidos a los nombres. Es el caso de Antoine de Rochetal, que en Le caractère par le prénom trata de dar a conocer la disciplina de la Onomatologie ?, e incluye unas curiosas «reglas onomatológicas» y una lista de nombres, con sus correspondientes rasgos.

Christian Bromberger (1982) estima que es en calidad de símbolo como el nombre se identifica a su portador en algunas sociedades, y subraya la precariedad de las reflexiones de la tradición onomástica en lo que se refiere a las funciones asignadas a los nombres propios. Según su acertado criterio, el sistema onomástico forma parte de la sociedad y de la cultura, lo que nos remite de nuevo al carácter clasificador y simbólico de los antropónimos.

7 A. Dauzat la denomina Onomancie (1925); Marc Wilmet (1997) definiría más tarde esta disciplina como « l'horoscope des prénoms". 


\section{LA TRADUCCIÓN DE LOS ANTROPÓNIMOS}

El amplio número de estudios teóricos dedicados a los nombres de persona contrasta con la mayor escasez de los que se ocupan de la problemática de su transferencia. Con la intención de contribuir a paliar dicho desequilibrio, este artículo se centra en el segundo aspecto, en el que se aprecia enseguida la diversidad de situaciones que se le pueden presentar al traductor.

Ya se ha señalado la tendencia general al mantenimiento de los nombres, pero conviene establecer diversas distinciones que matizan e incluso llegan a contradecir dicha tendencia.

Se puede establecer una clasificación global que, diferenciando a los nombres según su carácter real o ficticio, recoge a su vez las diversas contingencias que afectan a la transferencia de éstos.

\subsection{Los antropónimos reales}

En la transferencia de los antropónimos reales, no hay más que seguir las normas establecidas por el sistema linguístico de llegada. Por lo general, los nombres propios de persona no se transfieren, excepto en los casos en los que existe un equivalente institucionalizado, una forma consagrada, e incluso en esta eventualidad, la tendencia a la transcripción es creciente. Los nombres de denominación usual pueden tener equivalentes, en cuyo caso, más que de traducción, cabría hablar de correspondencia; así, numerosos antropónimos franceses tienen equivalentes en español, muchos de ellos con distinción genérica (Louis : Luis; Louise : Luisa; Pierre : Pedro; Claude : Claudio, Claudia), pero pueden no tenerlos (Armelle, Ginette).

Algunos nombres tienen una correspondencia ya consagrada, como los nombres de papas (Juan XXIII), de santos (San Pablo), de reyes o de príncipes (Luis XIV, Ana de Inglaterra); nombres de personajes renombrados en diversos terrenos como la política, el arte, la historia, la religión... (Miguel Ángel, Martín Lutero, Carlomagno, Copérnico); nombres de la Antigüedad (Tito Livio, Cicerón); nombres bíblicos (Ester, Marta, Holofernes, Herodes); apelativos históricos, dinastías (Juan sin Tierra, Pipino el Breve, los Capetos)... La mayoría de dichas equivalencias fueron adoptadas en épocas anteriores, y la tendencia actual es la de restringir tales adopciones.

\subsection{Los antropónimos ficticios}

En el caso de los nombres de persona de ficción, las modalidades de transferencia a otras lenguas dependen, por una parte, de factores como el tipo de 
texto, el género y la época considerada y, por otra, de su grado de opacidad o de transparencia.

Si se trata de nombres opacos, existe la posibilidad de transcribirlos, es decir, dejarlos tal como están (Sganarelle), o de naturalizarlos (Boleslas : Boleslao). La naturalización consiste en adaptar el nombre al sistema fonológico y gráfico de la lengua de llegada; basta la adjunción de un acento o el cambio de un grafema para naturalizar un nombre, integrándolo en el sistema de llegada. Los nombres usuales suelen seguir las mismas pautas que los nombres reales de persona en cuanto a la adopción de equivalentes.

Los nombres de persona pueden formar parte, en un contexto determinado, de una realidad cultural específica, y entrañar algún rasgo «nacional» que sin duda esperarán encontrar los lectores; en tal caso, que según E. Bernárdez (1987) se trataría de una «connotación de diversidad cultural», es exigible el mantenimiento de dicha connotación y la transcripción del nombre. Si se perdiera entonces un eventual simbolismo fonético o gráfico, se puede explicitar tal circunstancia en una nota.

La utilización de las técnicas de transferencia que han sido descritas: transcripción y naturalización, depende en gran medida del grado de conocimiento del nombre por parte de los receptores.

El procedimiento de la transliteración se aplica exclusivamente en los casos en que es necesario adaptar el nombre extranjero al sistema gráfico de llegada, respetando al mismo tiempo el sistema fonético original, lo que implica el conocimiento de las reglas de transliteración correspondientes a la lengua traducida. Así pues, los nombres escritos en alfabeto cirílico (búlgaro, ruso), o los que proceden del árabe, hebreo, griego, tailandés... deben ser transliterados para pasar a un sistema gráfico que no es el suyo. El sistema de romanización establecido para los caracteres chinos se denomina pinyin.

E. Bernárdez está en lo cierto al afirmar que la traducción es posible cuando el elemento connotativo prevalece sobre el elemento identificador, y enuncia la siguiente «macrorregla»: «El traductor deberá atenerse a la función que cumplen en el texto los nombres propios para reproducir esa función (...) en su traducción a otra lengua» (1987: 12). Dicha función, a la que el autor otorga un carácter comunicativo, se halla en relación directa con la intencionalidad que impregna los nombres propios, y que provoca que éstos transmitan determinados valores.

Algunos nombres poseen, pues, la capacidad de transmitir valores connotativos, que se pueden manifestar de diversas formas. Si el nombre refleja los mismos valores en la cultura de llegada, se puede transcribir o naturalizar (Ca- 
sanova, Gargantúa, Tartufo), pero si no suscita las mismas connotaciones o presenta una secuencia fonética inhabitual en la lengua receptora, puede ser sustituido por otro, dando lugar a una adaptación cultural (Stroumpf : «Pitufo»). Si es desconocido en la lengua de llegada, se adapta o se precisa su sentido mediante una breve información suplementaria al lado del nombre («es decir...») o mediante una nota al pie.

El nombre puede transmitir evocaciones exóticas, históricas, sensuales o literarias, que el traductor debe reproducir. Según el criterio de V. Moya: «... la obligatoriedad de traducir los nombres de ficción estará en proporción directa a la carga simbólica del signo de dicho nombre» (1993: 246).

Los únicos nombres que realmente se traducen son los transparentes, ya que transmiten un contenido conceptual, habitualmente connotativo, o unos valores fónicos, que es preciso reflejar (Monsieur Bonnefoy : «El señor Bonafé»; Rocquetaillade : «Rocatajo»; Grandgousier : "Grangaznate»).

Puede darse una asociación entre la fisionomía y los rasgos del personaje, lo que da lugar a frecuentes juegos de palabras. Es el caso de nombres muy conocidos, como Astérix, que evoca un asterisco; Obélix, un obelisco; Idéfix, una idea fija... En este caso, los procedimientos de traducción son muy diversos. En la literatura para niños, se tiende a mantener dichas connotaciones, y los nombres suelen tener correspondencias fijas: Caperucita, Cenicienta, Pulgarcito...

Un último procedimiento digno de mencionar es el de la recreación, que tiene lugar en determinados contextos. Ciertamente, no se puede hablar de traducción ni de adaptación con referencia a los textos vertidos por algunos autores españoles del siglo XVIII -a los que aludiremos más adelante-, sino de transferencia cultural y de auténtica recreación (Mariane : «Doña Pepita»).

Finalmente, hay que señalar la escasa utilidad del diccionario en el caso de la traducción de los antropónimos, que son tratados desde un punto de vista referencial, sin contemplar las diversas interpretaciones de que pueden ser objeto. Los nombres célebres o históricos son recogidos en encíclopedias y diccionarios especializados, no ofreciendo mayores problemas; en cuanto a los otros nombres, más usuales, se han de resolver en cada caso teniendo en cuenta las eventualidades expuestas, siempre en relación a su contexto.

\subsection{Aplicaciones}

Las modalidades de transferencia presentadas se han ilustrado con algunos antropónimos extraídos de las obras de diversos autores pertenecientes a 
distintas épocas, que han revelado una gran riqueza en este dominio. Juzgando de interés ampliar dicha ejemplificación y mostrar en la práctica la plural utilización de tales modalidades, vamos a dedicar este apartado a una exposición más detallada de las aportaciones de F. Rabelais, Molière, A. Jarry y R. Queneau como creadores de unos personajes que han sido transferidos siguiendo habitualmente un proceso paralelo en arte y creación.

Rabelais nos introduce en el reino de la comicidad y los juegos de palabras, tan presentes en la tradición medieval. François Rigolot señala: « La création onomastique se constate à chaque page de l'ouuvre de Rabelais " (1977: 83) y, ciertamente, son numerosos los nombres que, en su obra, transmiten determinados significados e imágenes auditivas.

Hemos manejado una edición de Gargantua en la que el traductor, ajustándose escrupulosamente a las normas del sistema linguíístico, reproduce la riqueza de los términos, tanto en lo que respecta al contenido conceptual como a los rasgos formales, no sólo en los nombres creados por Rabelais, sino también en los términos que incluyen rasgos dialectales o etimológicos. Presentamos algunos ejemplos.

Los nombres transcritos - reales o no- son escasos, puesto que se tiende a transferir todos los nombres, siempre que ello es posible. No faltan, sin embargo, los ejemplos: Jean Audeau (1) ${ }^{8}$, Jacques Coeur (5), Hugutio (14).

Entre los casos que disponen de equivalentes se cuentan algunos nombres usuales, como Bartolo (10), y, sobre todo, numerosos nombres de correspondencia consagrada por su carácter, como los de santos: ¡Por San Juan! (12), San Antonio (17), Santa Bárbara, San Jorge, Santiago (27); de papas: Alejandro (21); de reyes: Filipo (14), Sardanápalo (33); nombres bíblicos: Sansón (37), David (38), Moisés (50); mitológicos: Proserpina (2), Minerva, (6), Alcmena (3), Apolo (45), Hércules (46); u otros nombres de la Antigüedad, como Aristóteles $(14,39)$, Teofrasto, Nicandro (23), Diomedes (36), Temístocles (39), Estrabón (45).

Otros nombres se naturalizan. Incluimos, en este caso, el nombre francés, para apreciar el carácter de la naturalización: Gargantúa (Gargantua, 1), Guillote (Guillot, 5), Faquín (Fasquin, 14), Picrócolo (Picrochole, 26), Bayardo (Bayart, 39), Reinaldo (Regnault, 41 ).

Los nombres transparentes aparecen con asiduidad, como corresponde al carácter creador de Rabelais. Algunos de ellos, de origen griego, se naturalizan a partir de esta lengua, siguiendo el proceder del autor: Gimnasto (Gymnaste,

* Los números entre paréntesis corresponden al capítulo en el que se incluye el nombre citado. 
23), Sebasto (Sebaste, 48), Tolmero (Tolmere, 49), Rizótomo (Rhizotome, 23). Los nombres transparentes franceses pueden tener un origen dialectal: Rocatajo (Rocquetaillade, 6), Pollín (Pillot, 28), Rozagante (Prelinguand, 34), siendo capaces de transmitir imágenes sonoras junto a su contenido conceptual: Grangaznate (Grandgousier, 3), Gaznachona (Gargamelle, 3) o connotaciones humorísticas, como las presentes en los santos inventados, que Rabelais alterna con los santos reales: Santa Miamiga (Saincte Mamye, 17), San Hallado (Sainct Trouvé, 22), Santa Mosquitamuerta (Saincte Nytouche ${ }^{9}, 27$ ). Los nombres significativos se encuentran en gran número, por lo que presentamos una breve selección de ellos, precedidos de su traducción:

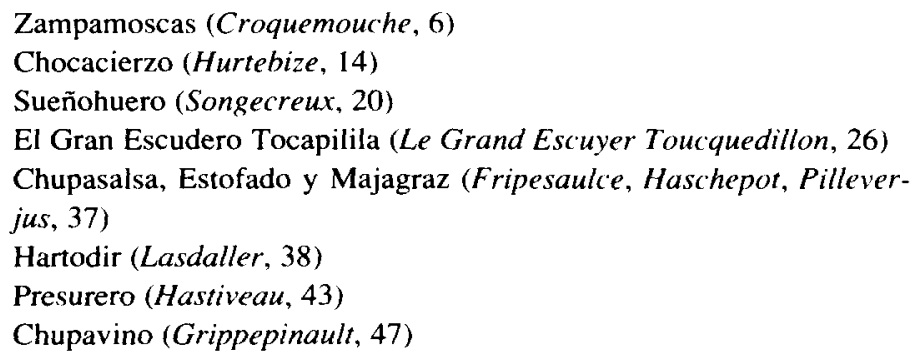

Hay que subrayar, por último, las adaptaciones culturales, como las que se llevan a cabo en el capítulo 22, en el que se describen los juegos de Gargantúa, como la gallina ciega (Colin Maillard, formado por dos nombres de persona).

Tras Rabelais, vamos a mostrar el arte de Molière como creador de personajes, lo que se pone de manifiesto en el Prólogo de la edición francesa utilizada: « ... Molière, en leur insufflant une vie individuelle qui les assimile aux êtres que nous rencontrons tous les jours, a élévé ses créatures à la hauteur de types humains, tout propres à figurer dans un monde physiognomonique » (1964:8).

Se han examinado diez textos del autor, a los que se ha asignado un número de orden, $y$, con objeto de captar los procedimientos de transferencia empleados, se han utilizado cinco ediciones españolas diferentes, que recogen una o varias de sus obras, coincidiendo en la selección en algunos casos. Se ha asignado, pues, una letra a dichas ediciones ${ }^{10}$ con el fin de evitar reiteraciones; pe-

` Esta designación ha venido a formar parte del acervo idiomático francés aplicada a « une personne qui joue l'innocence, hypocrite " y a " une femme qui joue les prudes " (Rey/Chantreau : Dictionnaire des expressions et locutions, Paris, Le Robert, 1986: 635).

10 En la bibliografía se indican los números y letras de orden de los correspondientes textos. 
ro es la primera de ellas (a) la que predomina en cuanto a ejemplos citados, ya que incluye las obras completas, reuniendo así los diez textos aludidos.

Algunos nombres son transcritos en las ediciones, con escasas diferencias:

Sganarelle $(1,4,5)$

Damis (3); Madama Pernelle (3a), Madame Pernelle (3c), Señora Pernelle (3d)

Ragotin (4)

El señor Filerin, el señor Macroton (5)

Lubin (6)

Oronte (8)

Dorante, el señor Jourdain (9)

El señor Diafoirus, el señor Fleurant (10)

Los casos de empleo de equivalentes - en nombres que disponen de correspondencia (nombres en cursiva)-, o de naturalización, son los más frecuentes:

Isabel, Aristo, Liseta, Valerio, Leonor (1 a), Doña Leonor (1b)

Horacio, Alán, Crisaldo (2)

Mariana, Orgón, Elmira. Tartufo (3); Felipota —en francés « Flipote $\gg$ - (3a/d), Felipa (3b), Flipot (3c)

Elvira, Perico (4a) —en francés « Pierrot »-, Pedrote (4e), Guzmán (4a), Don Alfonso (4a) - en francés « Dom Alonse », Don Alonso (4e) El señor Guillermo, el señor Tomés —en francés " Monsieur Tomès "-, el señor Desfonandrés —en francés « Monsieur des Fonandrès »-, el señor Bahis —en francés « Monsieur Bahys »- (5) Angélica, Claudina, Jorge Dandin, Clitandro (6)

Doña Claudia (7a), Señora Claudia (7e), Elisa (7), Harpagón, Cleanto - en francés « Cléante »- $(7 \mathrm{a})$, Cleantes $(7 \mathrm{e})$

Julia, Erasto (8)

Lucila, Nicolasa, Cleonte -en francés «Cléonte »-(9)

Angélica, Argán, Toñita (10)

Con el fin de ilustrar la traducción de los nombres transparentes hemos elegido los siguientes ejemplos:

Monsieur Loyal : Señor Leal (3a/ d); Monsieur Leal (3c)

Monsieur Dimanche : Don Domingo (4a); Señor Domingo (4e)"

La Flèche : Flecha $(7 \mathrm{a} / \mathrm{e})^{12}$

"Este nombre se ha lexicalizado en español y, como tal, es de empleo frecuente. En la edición (e) se indica en nota que figura en las actas notariales del siglo XVII como apellido.

12 Se trata de un nombre burlesco, ya que. como consta en la edición (e), el actor cojeaba. 
Brindavoine : Miajavena (7a); Pocavena (7e)

La Merluche : Merluza (7a/e)

Monsieur Purgon : El señor Purgón (10a)

Monsieur Bonnefoy : El señor Bonafé (10a) ${ }^{13}$

La segunda de las ediciones manejadas (b) comprende textos traducidos por Leandro Fernández de Moratín y por José Marchena, los cuales, en su calidad de autores neoclásicos, trasladan a Molière a la realidad y a la cultura españolas, dando lugar a una adaptación cultural, como muestran los correspondientes ejemplos. Moratín atribuye los siguientes antropónimos a los personajes de Molière en su obra La Escuela de los maridos:

Sganarelle : Don Gregorio

Ariste : Don Manuel

Isabelle : Doña Rosa

Léonor : Doña Leonor

Lisette : Juliana

Valère : Don Enrique

Ergaste : Cosme

José Marchena sigue el mismo procedimiento, consistente en «españolizar» los personajes y las situaciones. Fco. Javier Hernández, responsable de la edición, señala en la Introducción de ésta: «... Otro de los grandes aciertos de Marchena es el donaire con que sabe trasladar al español nombres de personajes» (1977: 36), lo que no impide a Hernández cambiar el nombre de Don Fidel por el de Tartufo, por razones de popularidad. Estos son los personajes de Tartufo o el hipócrita:

Madame Pernelle : Doña Tecla

Orgon : Don Simplicio

Elmire : Doña Elvira

Damis : Don Alejandro

Mariane : Doña Pepita

Valère : Don Carlos

Cléante : Don Pablo

Tartuffe : Tartufo

Dorine : Juana

Monsieur Loyal, sergent : Don Celedonio, escribano

Flipote : Felipa

${ }^{13}$ En este ejemplo y en el anterior, el traductor no ha tenido más que efectuar una naturalización para lograr el mismo efecto connotativo. Podría haberse empleado el mismo procedimiento en el caso de "Monsieur Fleurant». 
Las demás ediciones consultadas son bastante próximas, y las diferencias son mínimas, lo que se hace evidente en los ejemplos. La edición (a) no incluye indicaciones previas en torno a la traducción, pero el traductor, J. Gómez de la Serna, hace preceder las obras de notas alusivas a los textos, e incluye numerosas notas a pie de página que explicitan datos concretos - como el significado de Dandin, o el del nombre de los médicos representados por Molière en L'amour médecin-, y que a menudo justifican la traducción propuesta, bien por razones de eufonía (Agnès: Inés, 2; Flipote : Felipota, 3; Monsieur Josse : el señor José, 5), de adecuación (Dom Juan ou le festin de pierre : Don Juan o el convidado de piedra; Colin : Colasín, 6) o por otros motivos, como la imposibilidad de traducir (Ragotin, 4).

Las ediciones (d) y (e) tampoco explicitan criterios de traducción. El carácter de la edición (d) es muy elemental, mientras que la edición (e) incluye bastantes notas explicativas, algunas de las cuales han sido mencionadas. En ambas, los procedimientos seguidos son muy parecidos a los de la primera edición (a).

En la edición (c) se exponen, en cambio, unos criterios traductológicos que responden, por un lado, a un objetivo de fidelidad - con el único límite expreso de la claridad - y, por otro, a la voluntad de equilibrar la distancia temporal, con objeto de evocar el francés molieresco. Pero en esta edición, que sólo recoge Tartufo, los antropónimos, a los que hemos dedicado nuestra atención preferente, reflejan en escasa proporción el alcance de dichos criterios; es posible, sin embargo, detectar el deseado ambiente francés en el mantenimiento de los tratamientos (Madame Pernelle, Monsieur Leal).

Avanzando en el tiempo, merece la pena considerar la obra de Alfred Jarry, Ubu roi, en la que se detectan algunos rasgos rabelaisianos, presentes en el mismo léxico:

« bouzine " (cornemuse, «panza de Ubu»), « jambedieu » (interjección: «tabas de sátiro», 2: 145), « Jumelle » (lame, «lumela, espada»)...

En este caso hemos utilizado dos versiones españolas (asignándoles, igualmente, sendos números de orden), con objeto de comprobar si $U b u$ y los personajes que le acompañan han sufrido transformaciones en sus nombres, del mismo modo que las realizó en la obra de origen el mismo Jarry, quien, recogiendo diversas deformaciones del nombre de un profesor de su Instituto, le Père Hébert, colaboró a «construir» un nuevo antropónimo, que pasó por $\mathrm{Heb}$, Ébé y Eb..., hasta llegar a Ubu. 
Ni el padre ni la madre $U b u$ cambian de nombre, sufriendo como única transformación la naturalización mediante el acento en la versión 2 («Madre Ubú, Padre Ubú») - aunque la ausencia de acento en la primera versión se puede deber al uso de la mayúscula- Con respecto a los demás personajes, los siguientes antropónimos adoptan la correspondencia española o son naturalizados:

Le roi Venceslas : El rey Wenceslao (1), El rey Venceslao (2)

La reine Rosemonde : La reina Rosamunda (1/2)

Stanislas Leczinski : Estanislao Leczinski (1/2)

Jean Sobieski : Juan Sobieski (1/2)

Nicolas Rensky : Nicolas Rensky (1, en mayúsculas), Nicolás Rensky (2)

L'Empereur Alexis : El Emperador Alejo (1), El Emperador Alexis (2)

Michel Féderovitch : Miguel Federovitch (1/2)

Boleslas : Boleslao (1/2)

Ladislas : Ladislao (1/2)

Consideremos ahora los nombres transparentes. El tercero de los hijos del rey se llama Bougrelas, nombre cargado de significación, creado y destacado en la obra por Jarry, que le atribuye unos rasgos peculiares. En las versiones, el antropónimo se «traduce» al español (Bribonlao, 1) o es naturalizado, manteniendo así la proximidad con su forma y etimología originales (Bugrelao, 2).

Le capitaine Bordure y les Palotins, perdidas también las denominaciones españolas que tenían originariamente en la obrita escolar Les Polonais - fuente de $U b u$ roi-, adoptaron denominaciones heráldicas, evocadoras, con evidentes connotaciones sexuales. El capitán Bordure (antes Rolando) recuerda a ordure («basura, suciedad»), y a su vez, la bordure ("pièce en forme de ceinture qui environne tout l'écu... », 1978: 456) evoca al esfínter. De nuevo, la segunda versión se acerca más al término francés, privilegiando, en cierto modo, la connotación heráldica, es decir, simbólica:

Le capitaine Bordure : Capitán Brasura (1), Capitán Bordura (2)

Les Palotins, cuyos nombres primitivos eran Don Juan d'Avilar, Don Pedro de Morilla y Don Guzmán Alvarez, adoptaron los nombres simbólicos de Giron, Pile y Cotice, con connotaciones fálicas, y las versiones españolas han mantenido el mismo significado heráldico:

Giron, Pila, Cotiza (1); Jirón, Pila, Cotiza (2)

Se puede afirmar, en suma, que los antropónimos contenidos en la obra son reflejados sin grandes cambios en los textos españoles. La segunda versión 
es digna de mención no sólo por su texto, sino además por su introducción, aparato crítico y bibliografía, que aportan interesantes datos sobre el autor y el tema tratados. En dicha Introducción leemos: «Jarry le da la vuelta al verismo de la escena naturalista, e incluso simbolista, y lanza hacia el espectador la bomba de la etimología» (1997: 13).

Raymond Queneau sigue los pasos de Jarry, y se adhiere al «Colegio de Patafísica" - ciencia creada por este último- desde su creación. Queda, así, trazada una línea de escritores provocadores, de intención lúdica y voluntad desmitificadora: Rabelais-Jarry-Queneau, en la que no resulta descabellado incluir a Molière.

Queneau cuenta en sus Exercices de style una historia vulgar en noventa y nueve variantes, una de las cuales, llamada « Noms propres » ha atraído nuestra atención. Pues bien, el mismo texto se encuentra en la versión de Antonio Fernández Ferrer, quien lo sitúa entre los de obligada recreación, al tiempo que afirma su voluntad de buscar la mayor semejanza posible con respecto al texto de Queneau (1987: 38). Transcribimos ambos textos para terminar este apartado de aplicaciones, con objeto de ilustrar esta modalidad, mediante la cual se ofrece una alternativa que reproduce el sentido y el color del texto, reflejando así, a través del juego antroponímico, la intención del autor que lo ha creado.

« Noms propres »

Sur la Josephine arrière d'un Léon complet, j'aperçus un jour Théodule avec Charles le trop long et Gibus entouré par Trissotin et pas par Rubens. Tout à coup Théodule interpella Théodose qui piétinait Laurel et Hardy chaque fois que montaient ou descendaient des Poldèves. Théodule abandonna d'ailleurs rapidement Eris pour Laplace.

Deux Huyghens plus tard, je revis Théodule devant Saint-Lazare en grand Cicéron avec Brummell qui lui disait de retourner chez O'Rossen pour faire remonter Jules de trois centimètres.

\section{«Nombres propios»}

Un Domingo de Julio, tras hacer el Job esperando el Pegaso, no me encontré allí con Soledad precisamente, sino con Máximo Robustiano, un Gil Narciso nada Calisto que llevaba el Cascorro sin Jacinta. De pronto, este Carlomagno se enfadó, Severo y Bruto, pero no Clemente ni Benigno, con un Simplicio Matusalén muy Cándido e Inocencio además de Calvino, por culpa de Cayo Pisón. Pero, tras llamarle Comelio, decide ponerse Cómodo. 
Dos Horacios después, cuando yo iba sentado con Plácido y Augusto, volví a ver a Goliat, junto a Lázaro, mientras Petronio le aconsejaba, Facundo y con mucho Demóstenes, que fuera a Balenciaga para añadirse a Otón.

\section{CONCLUSIONES}

La capacidad que poseen los nombres propios de persona para transmitir connotaciones y valores diversos, que se ha defendido en el presente artículo, impone, cuando se considera su transferencia a otra lengua -en este caso, en la dirección: francés/español_-, el establecimiento de distintas modalidades según condicionamientos específicos.

En la realización de dicha transferencia, y particularmente en los ejemplos de ficción, hay que atender al trasvase de los referidos valores, que condicionan su funcionamiento según la intencionalidad del autor que los ha seleccionado.

Alain Rey afirma con acierto que un nombre propio no se traduce, « il ne peut, à la limite, que s'adapter » (1992: 28). De hecho, los procedimientos empleados para transferir un nombre a otra lengua no se pueden considerar realmente como una traducción, salvo en el caso de los nombres transparentes. En los demás casos, los antropónimos no se traducen; como se ha apuntado, encuentran su correspondencia con otros nombres según las normas del sistema lingüístico, o son transcritos, naturalizados, transliterados, adaptados a la cultura de llegada o incluso recreados.

La transferencia de los nombres depende de diversos condicionamientos. Ante un texto de ficción, hay que considerar algunos factores previos como el tipo de texto (cómico, serio, imaginativo...), el género (teatro, novela...), y la época en la que los antropónimos se hallan ubicados (Antigüedad, época contemporánea, siglo XVII...). En el pasado, imperaba la tendencia a la traducción, al contrario que en la actualidad; siguiendo dicha tónica, los autores del siglo XVIII español llevaban a cabo verdaderas recreaciones y transferían los datos culturales y con ellos, los nombres, a su propio universo. La consideración del género reviste a su vez una gran importancia, como lo demuestra, por ejemplo, el hecho de que los nombres se adapten habitualmente en los textos dramáticos, y en cambio, se transcriban cuando se trata de un «thriller» actual.

En el caso de los nombres opacos, conviene tener en cuenta particularmente el contexto, a fín de determinar si están situados en un marco general o si se trata de una realidad cultural específica que impide su transferencia.

Por otra parte, no es ocioso volver a subrayar la importancia que entraña la consideración de las indicaciones contenidas en cada tipo de texto, con ob- 
jeto de reproducir los valores cómicos, exóticos, fónicos o morfológicos de los nombres en él comprendidos.

Es necesario, en suma, respetar en todos los casos la función del nombre en su contexto, que habitualmente viene determinada por la intencionalidad del autor, y seguir el procedimiento utilizado en el antropónimo francés.

\section{REFERENCIAS BIBLIOGRÁFICAS}

Barthes, Roland (1953): Oeuvres complètes. Tome I. Paris, éd. Du Seuil.

BERNÁRDEZ, Enrique (1987): «El nombre propio: su función y su traducción», Problemas de la traducción (Mesa redonda). Madrid, Fundación «Alfonso X el Sabio», pp. 11-21.

Bromberger, Christian (1982): “Pour une analyse anthropologique des noms de personnes », Langages, 66. Le Nom Propre, pp. 103-124.

BUYSSENS, Eric (1973): «Les noms singuliers », Cahiers Ferdinand de Saussure, 28, pp. 25-34.

CANTERa Ortiz de Urbina, Jesús (1987): «La problemática de los nombres propios en la traducción del francés al español», Problemas de la traducción (Mesa redonda). Madrid, Fundación «Alfonso X el Sabio», pp. 23-31.

CANTERA OrTIZ de URBina, Jesús (1995): «La problemática de los nombres propios en la traducción», en Édith Le Bel (éd.): Le masque et la plume. Traducir: Reflexiones, experiencias y prácticas. Universidad de Sevilla, pp. 161-176.

Dauzat, Albert (1925): Les noms de personnes. Origine et évolution. Prénoms. Noms de famille. Surnoms. Pseudonymes. Paris, Librairie Delagrave.

Espinal, M. ${ }^{a}$ Teresa (1992): «Sobre la traducción de los nombres propios», Cuadernos de Traducción e Interpretación, 11-12, pp. 73-93.

Gary-Prieur, Marie-Noëlle (1989): «Quand le référent d'un nom propre se multiplie », Modèles linguistiques. Tome XI, Fascicule 2, pp. 119-133.

GARY-PrieuR, Marie-Noëlle (1991a): « Le nom propre constitue-t-il une catégorie linguistique? », Langue Française, 92, pp. 5-25.

Gary-Prieur, Marie-Noëlle (1991b): « La modalisation du nom propre ", Langue Française, 92, pp. 46-63.

JONASSON, Kerstin (1991): « Les noms propres métaphoriques : construction et interprétation ", Langue Française, 92, pp. 64-81.

JONASSON, Kerstin (1994): Le nom propre. Constructions et interprétations. Belgique, Duculot.

Kerbrat-Orecchioni, Catherine (1977): La connotation. 3e éd. Presses Universitaires de Lyon.

KLEIBER, Gerges (1991): “ Du nom propre non modifié au nom propre modifié : le cas de la détermination des noms propres par l'adjectif démonstratif », Langue Française, 92, pp. 82-103. 
KLEIBER, Gerges (1996): « Noms propres et communs : un problème de dénomination », Meta, Numéro spécial : La dénomination. Vol. 41, n. ${ }^{\circ} 4$, pp. 567-589.

KRIPKE, Saul (1982): La logique des noms propres. Traduit de l'américain par Pierre Jacob et François Recanati (Naming and Necessity, 1972, 1980). Paris, éditions de Minuit.

LÓPEZ GARCía, Ángel (1985): «Lo propio del nombre propio», Lingüística española actual. VII/ 1, pp. 37-54.

Mill, John Stuart (1988): Système de logique déductive et inductive. 2 Tomes. Reéd. de la traduction française de 1866 (celle-ci traduite sur la sixième édition anglaise par Louis Peisse, Paris, Librairie Philosophique de Ladrange). Paris, Pierre Mardaga.

Molino, Jean (1982): "Le nom propre dans la langue ", Langages, 66. Le Nom Propre. pp. 5-20.

Moya, Virgilio (1993): «Nombres propios: su traducción», Revista de Filología de la Universidad de La Laguna, 12, pp. 233-247.

MoyA, Virgilio (2000): La traducción de los nombres propios. Madrid, Cátedra.

RECANATI, François (1983): « La sémantique des noms propres. Remarques sur la notion de désignateur rigide ». Langue Française, 57, pp. 106-118.

REY, Alain (1992); La terminologie : noms et notions (2e éd. corrigée). Paris, PUF.

Rigolot, François (1977): Poétique et onomastique. L'exemple de la Renaissance. Genève, Droz.

RoCHETAL, Antoine de (1929): Le caractère par le prénom, contenant la liste des prénoms usuels avec les qualités et défauts qu'ils imposent à ceux qui les portent. Paris, éd. Montaigne.

SwigGers, Pierre (1989): «Une classe de noms propres : les ' rétrolocutifs ' ". Nouvelle revue d'onomastique, 14, pp. 157-164.

VROONEN, Eugène (1967): Les noms de personnes dans le monde. Anthroponymie universelle comparée. Bruxelles, éditions de la Librairie encyclopédique.

WiLmet, Marc (1991): « Nom propre et ambigüité », Langue Française, 92, pp. 113124.

YNDURAIN, Francisco (1992): «Comparativismo y poligénesis», Sociedad Española de Literatura general y comparada, pp. 13-22.

FUENTES PARA LOS EJEMPLOS DE FICCIÓN Y APLICACIONES

JARRY, Alfred (1978): Ubu. Ubu roi, Ubu cocu, Ubu enchaîné, Ubu sur la Butte, publiés sur les textes définitifs établis, présentés et annotés par Noël Armand et Henri Bordillon. Paris, Gallimard.

1. JARRY, Alfred (1976): Ubu rey. Traducción de Nuria Guardiet. Barcelona, Producciones Editoriales. 
2. JARRY, Alfred (1997): Ubú rey. Edición de Lola Bermúdez. Traducción de José Benito Alique. Madrid, Cátedra.

La Fontaine (1990): Fables choisies mises en vers. Paris, Gamier Frères.

MOLIÈre (1963-64): Théâtre complet. IV Tomes. Paris, Librairie générale française :

1. L'école des maris

2. L'école des femmes

3. Le tartuffe ou l'Imposteur

4. Dom Juan ou le festin de pierre

5. L'amour médecin

6. George Dandin

7. L'Avare

8. Monsieur de Pourceaugnac

9. Le Bourgeois gentilhomme

10. Le malade imaginaire

(a) Molière (1991): Obras completas. Recopilación, traducción, estudio preliminar y censo de personajes por Julio Gómez de la Serna. Madrid, Aguilar. $1 .^{a}$ ed. 1945.

(b) Molière (1977): Tres comedias (La Escuela de los maridos, adaptación de Leandro Fernández de Moratín; La Escuela de las mujeres, traducción española de José Marchena; Tartufo o el Hipócrita, traducción española de José Marchena). Edición preparada por Francisco Javier Hernández. Madrid, Editora Nacional.

(c) Molière (1996): Tartufo. 9. ${ }^{a}$ ed. Edición y traducción de Encarnación García Fernández y Eduardo J. Fernández Montes. Madrid, Cátedra.

(d) Molière (1984): Tartufo o el Impostor. Edición preparada por Miguel Sagües. San Sebastián, Haranburu editor.

(e) Molière (1998): Don Juan. El avaro. Edición y traducción de Mauro Armiño. Madrid, Espasa Calpe.

Queneau, Raymond (1997): Exercices de style. Paris, Gallimard. 1.a ed. 1947.

QUENEAU, Raymond (1987): Ejercicios de estilo. 2. ${ }^{a}$ ed. Versión y estudio introductorio de Antonio Fernández Ferrer. Madrid, Cátedra.

RabelaIS, François (1962): Oeuvres complètes. Tome I. Paris, Garnier.

RabelaIS, François (1999): Gargantúa. Ed. de Alicia Yllera. Madrid, Cátedra. 